\title{
Excessive recreational computer use and food consumption behaviour among adolescents
}

\author{
Lu Shi ${ }^{*}$, Yuping Mao ${ }^{2}$
}

\begin{abstract}
Introduction: Using the 2005 California Health Interview Survey (CHIS) data, we explore the association between excessive recreational computer use and specific food consumption behavior among California's adolescents aged 12-17.

Method: The adolescent component of CHIS 2005 measured the respondents' average number of hours spent on viewing TV on a weekday, the average number of hours spent on viewing TV on a weekend day, the average number of hours spent on playing with a computer on a weekday, and the average number of hours spent on playing with computers on a weekend day. We recode these four continuous variables into four variables of "excessive media use," and define more than three hours of using a medium per day as "excessive." These four variables are then used in logistic regressions to predict different food consumption behaviors on the previous day: having fast food, eating sugary food more than once, drinking sugary drinks more than once, and eating more than five servings of fruits and vegetables. We use the following variables as covariates in the logistic regressions: age, gender, race/ethnicity, parental education, household poverty status, whether born in the U.S., and whether living with two parents.
\end{abstract}

Results: Having fast food on the previous day is associated with excessive weekday TV viewing (O.R. $=1.38, p<$ 0.01). Having sugary food more than once is associated with excessive weekend TV viewing (O.R. $=1.50, p<$ $0.001)$. Having sugary drinks more than once is associated with excessive weekday TV viewing (O.R. $=1.41, p<$ 0.01 ), excessive weekday recreational computer use $(O . R .=1.38, p<0.05)$, and excessive weekend TV viewing (O.R. $=1.43, p<0.001$ ). Finally, having more than five servings of fruits and vegetables on the previous day is negatively associated with all four media use variables: excessive weekday TV viewing (O.R. $=0.64, p<0.001)$, excessive weekday recreational computer use (O.R. $=0.68, p<0.01)$, excessive weekend TV viewing $(O . R .=0.80, p<0.05)$, and excessive weekend recreational computer use (O.R. $=0.78, p<0.05)$.

Conclusion: Excessive recreational computer use independently predicts undesirable eating behaviors that could lead to overweight and obesity. Preventive measures ranging from parental/youth counseling to content regulations might be addressing the potential undesirable influence from excessive computer use on eating behaviors among children and adolescents.

\section{Introduction}

A possible association between one's excessive computer use and his or her obesity risk has been noted in earlier studies $[1,2]$. However, the exact pathways between computer use and obesity had remained unclear. While one's time spent in front of the computer screen might be at the expense of physical activity (the "physical

\footnotetext{
* Correspondence: lushi.pku@gmail.com

'Department of Health Services, 650 Charles E. Young Drive S. 61-253 CHS,

University of California Los Angeles, Los Angeles, CA 90095, USA

Full list of author information is available at the end of the article
}

activity displacement hypothesis"), it is also very likely that Internet food advertisements lure people to make suboptimal food choices and in turn increased their bodyweight [3] (the "media change intake" hypothesis). Meanwhile, eating and drinking in front of a screen might easily promote snacking and overeating [4-6]. A necessary condition for the "media change intake" hypothesis to hold is the evidence for an association between specific food intake patterns and time spent on computer use, yet no study to date has looked at this type of associational patterns. To fill this research gap,

\section{Biomed Central}


this paper explores whether excessive computer predicts consumption of fast food, sugar-sweetened beverage, high-sugar foods, and fruits and vegetables.

\section{Method}

We use the 2005 adolescent sample of California Health Interview Survey (CHIS), the only population survey dataset we know to have measured both media consumption behavior and food consumption patterns among adolescents, to explore the association between excessive recreational computer use and specific food consumption. CHIS is a biennial population health survey [7], and its adolescent sample is collected via telephone interviews with adolescents living in sampled households.

The adolescent component of CHIS 2005 measured the respondents' average number of hours spent on viewing TV on a weekday, the average the average number of hours spent on viewing TV on a weekend day, the average number of hours spent on playing with a computer on a weekday, and the average number of hours spent on playing with computers on a weekend day. We recode these four continuous variables into four dummy variables of "excessive media use," and define more than three hours of using a medium per day as "excessive" since this is the threshold where media consumption predicts health-related behavior [8]. These four dummy variables are then used in logistic regressions to predict different food consumption behaviors on the previous day. While the key independent variables here are excessive weekday recreational computer use and excessive weekend recreational computer use, the two variables about excessive TV viewing are used as covariates to control for their confounding effects. We use four logistic regressions to predict the following four food consumption behaviors:

1. Having had fast food the day before (recoded from the CHIS survey item "Yesterday, how many times did you eat fast food? Include fast food meals eaten at school, at home or at fast-food restaurants, carryout or drive thru.")

2. Having had sugary food more than once the day before (recoded from the survey item "How many servings of high sugar foods, such as cookies, candy, doughnuts, pastries, cake or popsicles did you have?")

3. Having had sugary drinks more than once the day before (recoded from the survey item "Yesterday, how many glasses or cans of soda, such as Coke, or other sweetened drinks, such as fruit punch or Sunny Delight did you drink? Do not count diet drinks.")

4. Having had five or more servings of fruits and vegetables as per the Center of Disease Control and
Prevention instruction [9] (recoded from two survey items: "Yesterday, how many servings of fruit, such as an apple or banana did you eat?" and "Yesterday, how many servings of vegetables, like corn, green beans, green salad, or other vegetables did you eat?").

We use the following variables as covariates in the four logistic regressions: age, gender, race/ethnicity, parental education, household poverty status (below federal

\section{Table 1 Demographic and Behavioural Profile of the Study Sample}

\begin{tabular}{lr}
\hline Variable & $\begin{array}{r}\text { Percent/mean } \begin{array}{r}\text { (standard } \\
\text { error) }\end{array} \\
\hline \text { Male }\end{array}$ \\
Age & $50.9 \%$ \\
Race/ethnicity & $14.41(.026)$ \\
White & \\
Latino & \\
Asian & $53.3 \%$ \\
Black & $21.1 \%$ \\
Other & $8.8 \%$ \\
& $5.8 \%$ \\
& $11.0 \%$
\end{tabular}

Parental education

Less than high school $\quad 36.9 \%$

High school $\quad 21.3 \%$

Some college $\quad 26.4 \%$

College graduate $\quad 15.5 \%$

Below federal poverty line $\quad 12.0 \%$

Living with two parents $\quad 69.8 \%$

Born in the United States $\quad 90.2 \%$

Food/beverage consumption the day before

Had fast food $\quad 39.0 \%$

Had high-sugar food more than once $\quad 33.8 \%$

Had sugary drinks more than once $\quad 30.6 \%$

Had fruits and vegetable for five $\quad 25.0 \%$

servings or more

Daily hrs on TV-video/weekday 1.97 (.026)

Daily hrs on computer/weekday $\quad 1.36(.025)$

Daily hrs on TV-video/weekend 2.77 (.035)

Daily hrs on computer/weekend 1.61 (.030)

$N=4029$ 
poverty line $=1$ ), whether born in the United States [10], and whether living with two parents [11].

\section{Results}

Table 1 lists the descriptive statistics for the predictor variables. Among the 4029 adolescents surveyed, 39.0\% reported having fast food on the previous day, 33.8\% reported having high-sugar food on the previous day, $30.3 \%$ reported having sugary drink on the previous day, and $25.0 \%$ reported having five servings of fruits and vegetables on the previous day.

Table 2 shows the logistic regression results for the four models. Having fast food on the previous day is associated with excessive weekday TV viewing (O.R. = $1.38, \mathrm{p}<0.01$ ), which means for an adolescent who viewed more than three hours of TV per weekday the odds of having fast food is $38 \%$ bigger than those who did not view as much. Having sugary food more than once is associated with excessive weekend TV viewing $(\mathrm{O} . \mathrm{R} .=1.50, \mathrm{p}<0.001)$. Having sugary drinks more than once is associated with excessive weekday TV viewing (O.R. $=1.41, \mathrm{p}<0.01)$, excessive weekday recreational computer use (O.R. $=1.38, \mathrm{p}<0.05)$, and excessive weekend TV viewing $(\mathrm{O} . \mathrm{R} .=1.43, \mathrm{p}<0.001)$. Finally, having more than five servings of fruits and vegetables on the previous day is negatively associated with all four media use variables: excessive weekday TV viewing $(\mathrm{O} . \mathrm{R} .=0.64$, $\mathrm{p}<0.001$ ), excessive weekday recreational computer use (O.R. $=0.68, \mathrm{p}<0.01)$, excessive weekend $\mathrm{TV}$ viewing $(\mathrm{O} . \mathrm{R} .=0.80, \mathrm{p}<0.05)$, and excessive weekend recreational computer use (O.R. $=0.78, \mathrm{p}<0.05)$.

\section{Discussion}

As our logistic regressions show, excessive recreational computer use independently predicts undesirable eating behaviors that could lead to overweight and obesity $[12,13]$, even when we control for television viewing and socio-demographic covariates. These results are consistent with previous studies of television viewing and unhealthy eating behavior $[6,14,15]$. The literature on

Table 2 Logistic Regressions of Food Consumption among Adolescents in California ( $\mathbf{N}=\mathbf{4 0 2 9}$ )

\begin{tabular}{|c|c|c|c|c|}
\hline & $\begin{array}{l}\text { Eating } \\
\text { fast food } \\
\text { yesterday }\end{array}$ & $\begin{array}{l}\text { High-sugar food more than once } \\
\text { yesterday }\end{array}$ & $\begin{array}{l}\text { Sugary drink more than once } \\
\text { yesterday }\end{array}$ & $\begin{array}{l}>5 \text { servings of fruit/vegetable } \\
\text { yesterday }\end{array}$ \\
\hline & Odds Ratios & Odds Ratios & Odds Ratios & $\begin{array}{l}\text { Odds } \\
\text { Ratios }\end{array}$ \\
\hline Gender (female $=1$ ) & 0.91 & $1.15^{*}$ & $0.61^{* *}$ & 0.98 \\
\hline Age & $1.05^{* *}$ & 0.98 & $1.09^{* *}$ & $0.89^{* *}$ \\
\hline \multicolumn{5}{|l|}{ Parental Education } \\
\hline $\begin{array}{l}\text { Less than high } \\
\text { school }\end{array}$ & Ref. & Ref. & Ref. & Ref. \\
\hline High school & 1.17 & 0.95 & 1.20 & 0.85 \\
\hline Some college & 1.17 & 0.89 & 0.98 & $0.76^{* *}$ \\
\hline College graduate & $0.73^{*}$ & 1.02 & $0.63^{* *}$ & $1.25^{*}$ \\
\hline \multicolumn{5}{|l|}{ Race/Ethnicity } \\
\hline White & Ref. & Ref. & Ref. & Ref. \\
\hline Latino & $1.54^{* *}$ & 0.91 & $1.37^{* *}$ & 0.90 \\
\hline Black & $1.46^{* *}$ & 1.22 & $1.63^{* *}$ & $0.64^{* *}$ \\
\hline Asian & 1.18 & 0.84 & 0.77 & $1.36^{* *}$ \\
\hline American Indian & 1.13 & 1.20 & $1.31^{*}$ & 1.03 \\
\hline Pacific Islander & 1.45 & 0.83 & 0.73 & 0.70 \\
\hline Other & $1.34^{*}$ & 1.05 & $1.53^{* *}$ & $0.77^{*}$ \\
\hline Below poverty line & 0.87 & 1.05 & $0.77^{*}$ & 1.07 \\
\hline Born in the US & 1.02 & 1.06 & 1.29 & 0.93 \\
\hline Living with two parents & 1.01 & 1.10 & 0.86 & $1.19^{*}$ \\
\hline TV $>3$ hrs weekday & $1.38^{* *}$ & 1.20 & $1.41^{* *}$ & $0.64^{* *}$ \\
\hline $\begin{array}{l}\text { Computer }>3 \text { hrs } \\
\text { weekday }\end{array}$ & 1.11 & 1.08 & $1.38^{*}$ & $0.68^{* *}$ \\
\hline TV $>3$ hrs weekend day & 1.09 & $1.50^{* *}$ & $1.43^{* *}$ & $0.80^{* *}$ \\
\hline $\begin{array}{l}\text { Computer }>3 \text { hrs } \\
\text { weekend day }\end{array}$ & 1.20 & 1.02 & 1.21 & $0.78^{*}$ \\
\hline
\end{tabular}

Note:

*: $p$-value is less than .05

**: $p$-value is less than .01 
television and unhealthy intake indicated that sugary food and beverage are more likely to reach the young audience and change their intake behavior via advertisement than fruits and vegetables [16-18]. This mechanism of "media content changes behavior" might also explain the association between recreational computer use and unhealthy intake as well, as Internet food advertisements show a similar content pattern to that of television commercials [3]. Another explanation for the association between sugary drinks and excessive computer use on weekdays could that the long duration of gaming in front of a screen necessitates the intake of caffeinated drinks like coca-cola [19], especially if the computer use occurs during weekdays when adolescents are more likely to play video games or web games at night. In other words, drinking caffeinated sugary drinks might enable gamers to stay longer in front of the computer screen and hence the association between sugary drink consumption and the time spent on recreational computer use.

This is the first study, to the best of our knowledge, to explore the association between recreational computer use and specific food/drink consumption patterns among adolescents. As the society attempts to address the digital divide by providing more computer access to younger populations, the content of computer games and the Internet remains largely unregulated as compared with traditional media like TV. The traditional media channels like TV now have various restrictions and technical devices to limit children's exposure to food commercials, yet much less attention has been paid to the food advertisement on the Internet, a media channel extremely popular among younger populations. Moreover, if children who are at risk of being overweight are more likely to live in households where parents might have less technical knowledge and time available to monitor children's computer use, then the introduction of computers and the Internet could have magnified the existing disparities in the current obesity epidemic. Thus, it might be advisable to adopt more preventive measures, including youth counseling and content regulations, to address the potential undesirable influence from excessive computer use on eating and drinking behaviors among children and adolescents.

\footnotetext{
Author details

${ }^{1}$ Department of Health Services, 650 Charles E. Young Drive S. 61-253 CHS, University of California Los Angeles, Los Angeles, CA 90095, USA.

${ }^{2}$ Department of Communications and Technology, Enterprise Square, University of Alberta, 10230 Jasper Avenue, Edmonton, Alberta, T5J 4P6, Canada.
}

\section{Authors' contributions}

Lu Shi contributed the data analysis and Yuping Mao contributed the literature review. All authors have read and approved the final manuscript.

\section{Competing interests}

The authors declare that they have no competing interests.

Received: 14 May 2010 Accepted: 5 August 2010

Published: 5 August 2010

\section{References}

1. Mendoza J, Zimmerman F, Christakis D: Television viewing, computer use, obesity, and adiposity in US preschool children. International Journal of Behavioral Nutrition and Physical Activity 2007, 4(1):44.

2. Anderson S, Economos C, Must A: Active play and screen time in US children aged 4 to 11 years in relation to sociodemographic and weight status characteristics: a nationally representative cross-sectional analysis. BMC Public Health 2008, 8(1):366.

3. Weber K, Story M, Harnack L: Internet Food Marketing Strategies Aimed at Children and Adolescents: A Content Analysis of Food and Beverage Brand Web Sites. Journal of the American Dietetic Association 2006, 106(9):1463-1466.

4. Wansink B, Park SB: At the movies: how external cues and perceived taste impact consumption volume. Food Quality and Preference 2001, 12(1):69-74.

5. Francis LA, Lee $Y$, Birch LL: Parental Weight Status and Girls/' Television Viewing, Snacking, and Body Mass Indexes. Obesity 2003, 11(1):143-151.

6. Salmon J, Campbell KJ, Crawford DA: Television viewing habits associated with obesity risk factors: a survey of Melbourne schoolchildren. Medical Journal of Australia 2006, 184:64-67.

7. Ponce NA, Lavarreda SA, Yen W, Brown ER, DiSogra C, Satter DE: The California Health Interview Survey 2001: translation of a major survey for California's multiethnic population. Public Health Reports 2004, 119(4):388-95.

8. Gidwani PP, Sobol A, DeJong W, Perrin JM, Gortmaker SL: Television Viewing and Initiation of Smoking Among Youth. Pediatrics 2002, 110(3):505-508.

9. 5 a day works! Atlanta (GA): U.S. Department of Health and Human Services, Center for Disease Control and Prevention. 2005 [http://www. cdc.gov/nccdphp/dnpa/nutrition/health_professionals/programs/ 5Aday_Works.pdf], [Accessed on July 31, 2010].

10. Popkin BM, Udry JR: Adolescent Obesity Increases Significantly in Second and Third Generation U.S. Immigrants: The National Longitudinal Study of Adolescent Health. J Nutr 1998, 128(4):701-706.

11. Strauss RS, Knight J: Influence of the Home Environment on the Development of Obesity in Children. Pediatrics 1999, 103(6):e85.

12. Jeffery RW, French SA: Epidemic obesity in the United States: are fast foods and television viewing contributing? Am J Public Health 1998, $88(2): 277-280$.

13. Malik VS, Schulze MB, Hu FB: Intake of sugar-sweetened beverages and weight gain: a systematic review. Am J Clin Nutr 2006, 84(2):274-88.

14. Giammattei J, Blix G, Marshak HH, Wollitzer AO, Pettitt DJ: Television Watching and Soft Drink Consumption: Associations With Obesity in 11to 13-Year-Old Schoolchildren. Arch Pediatr Adolesc Med 2003, 157(9):882-886.

15. Boynton-Jarrett R, Thomas TN, Peterson KE, et al: Impact of Television Viewing Patterns on Fruit and Vegetable Consumption Among Adolescents. Pediatrics 2003, 112(6):1321-1326.

16. Taras HL, Sallis JF, Patterson TL, Nader PR, Nelson JA: Television's influence on children's diet and physical activity. Dev Behav Pediatr 1989, 10:176-180.

17. Borzekowski DL, Robinson TN: The 30-second effect: an experiment revealing the impact of television commercials on food preferences of preschoolers. J Am Diet Assoc 2001, 101:42-46.

18. Hill JM, Radimer KL: A content analysis of food advertisements in television for Australian children. Aust J Nutr Diet 1997, 54:174-181.

19. Porter $G$, Starcevic $V$, Berle $D$, Fenech $P$ : Recognizing problem video game use. Aust N Z J Psychiatry 2010, 44(2):120-8.

doi:10.1186/1824-7288-36-52

Cite this article as: Shi and Mao: Excessive recreational computer use and food consumption behaviour among adolescents. Italian Journal of Pediatrics 2010 36:52. 